\title{
Evaluation of Overall Stability for Garage Foundation Excavation of High Buildings
}

\author{
Han Yunshan*, Wu Han, Dong Yanli and Wang Yuanlong \\ School of Science, North University of China, Taiyuan, Shanxi, 030051, P.R. China
}

\begin{abstract}
In current projects, many garages were built after the main structure finished. However, the excavation of garage foundation not only changed the bearing capacity modification by depth, but also makes the soil pressure along the two sides become different. And thus the stress condition of the main building foundations is changed. The change of stress condition affects the stability of main structure directly. Based on the stress condition of high buildings foundation after one side excavation, the change of settlement under the eccentric action was studied. The change of settlement makes the tilt turning appear and thus makes the overturning resistance moment change. The dynamic principle of stability safety factors were also investigated in this paper. The effect of settlement affected by the change of stress condition was considered in the stability analysis of high building. This new method can better and truly evaluate the effect of excavation of foundation on the stability of overturning resistance than the traditional method considering only the static load-carrying capability. The operation of the new method is stronger in the project application for its clear mechanism.
\end{abstract}

Keywords: Dynamic, foundation, overturning, settlement, stability.

\section{INTRODUCTION}

At present, along with the rapid increase in urban construction, various requirements of the construction of underground garage in residential areas have been realized. In accordance with the requirements of engineering construction, it is more reasonable that the main structure, the podium and the garage are constructed simultaneously. But for various reasons, in real projects, many podium and garages have been built after the main structure is finished, which inevitably involves the main structure stability evaluation problem after the excavation of foundation pit. It is common that the main structure uses the natural foundation or composite foundation. After excavating of the garage foundation at one side of the main structure, the bearing capacity modification by depth of the main structure will be weaken or even becomes zero. The first problem we should be considered is the bearing capacity of the foundation of the established main structure (i.e. strength problems). Once the excavation depth of the garage exceeds the position of basement, the situation will become more complicated. Secondly, the soil pressure differences under the main structure will appear after one side excavation of the foundation pit of garage. And also, the stress conditions of the main structure foundation will be changed. The soil additional stress of foundation was changed correspondingly. Further, the compressible deformation of foundation may be changed. All of these changes will make the foundation have a tendency to tilt, which leads to the change of overturning resistance moment. During this process, the overall stability safety factor of high buildings will be changed.

*Address correspondence to this author at the School of Science, North University of China, Taiyuan, Shanxi, 030051,P.R. China; Tel/Fax: +86 351 3923593; E-mail: hyswzr@163.com
For many projects used natural foundation or composite foundation, only the bearing capacity modification by depth of the main structure is considered. The effect of stability of the main structure usually is ignored. Or, the effect would be considered from the view of static analysis. The effect of soil pressure difference along the two sides of the main structure caused by excavation of the podium and the garage, was not paid much attention by most researchers. Therefore, how to evaluate the overall stability of the main structure reasonably became a hot and difficult problem which involved the use of foundation supporting and soil reinforcement during excavation of the garage foundation pit. And no matter what kind of technology is adopted, the economical and secure issues should be involved. Focused on the overall stability of foundation, the standard [1] gives clear requirements of the foundation stability. Many researchers [2-6] had published related papers. Bodaqhi [7] and Chu [8] studied the stability of the flexible foundation using the theory method by changing the parameters of foundation and material properties. Ma [9], Feng [10], Devolder [11] and Chem [12] analyzed the process of excavation. However, most researchers focused on the strength and bearing capacity, and fewer researchers considered the coordination between the deformation and stress of foundation. Some researchers [13-16] had studied the design of foundation of high buildings. Based on the horizontal stress conditions of high buildings foundation after one side excavation, the change of settlement under the eccentric action was studied. The tilt turning and the overturning resistance moment due to the change of settlement were investigated. The dynamic principle of stability safety factors were also investigated in this paper. The dynamic analysis of stability of high buildings considered the effects of settlement affected by the horizontal stress condition, can better evaluate the effect of excavation of foundation on the stabil- 
ity of overturning resistance compared with the traditional method considering the static load-carrying capability. This new method with clear mechanism has better practical application in the project.

\section{STABILITY EVALUATION CONSIDERING STRESS}

What has to be illustrated first is that the overturning resistance of the high buildings considered in this paper, refers to direction of the foundation width. Assume that no eccentric and no eccentricity existed, that is to say the point of the resultant force $G$ produced by various combinations in the main structure initially is in the center of the cross section, and the vertical force goes through the center of the basement. At the same time, if we assume that the stiffness of main structure and foundation is large enough, settlement is uniform. The pressure distributed evenly is equal to reaction acts in a contrary direction. The soil pressures along the two sides of buildings are also equal in size and opposite in direction. At this time, the forces balance, and the moment produced by forces around A also balance, as shown in Fig. (1).

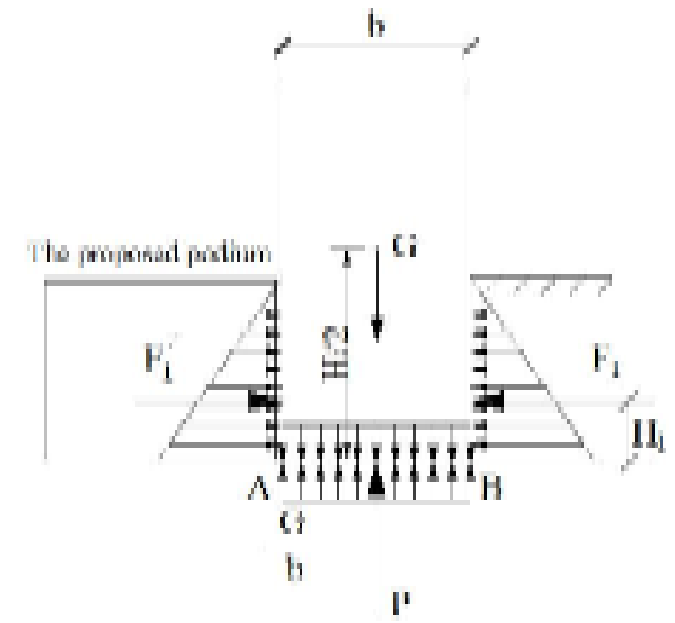

Fig. (1). Foundation of high buildings without excavation.

The overturning moment of the main structure $M_{1}$ was equal to zero. The overturning resistance moment produced by the upper resultant force $\mathrm{G}$ around $\mathrm{A}$ was shown as follows:

$$
M=\frac{b}{2} G
$$

The overall stability safety factor of main body was shown as follows:

$$
K=\frac{M}{M_{1}}=\frac{\frac{b}{2} G}{0}=\infty
$$

Safety factor was "infinite". After excavation of one side foundation pit, the soil pressure along the two sides of the main structure produces pressure difference. The overturning moment produced by net earth pressure around point A can be expressed as follows:

$$
M_{2}=F_{2} \cdot H_{2}
$$

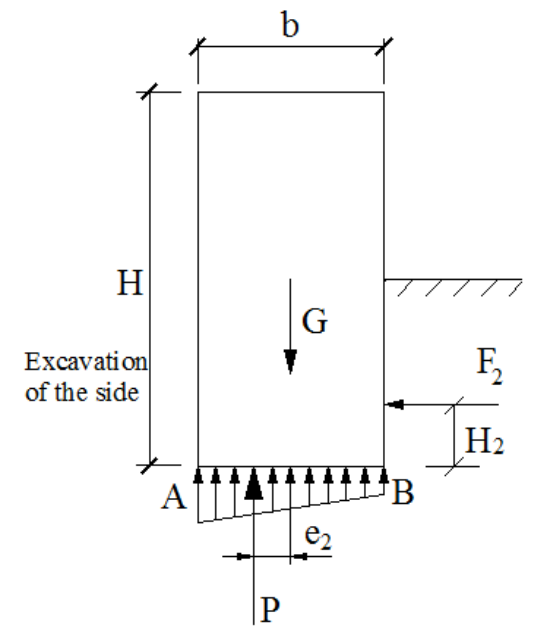

Fig. (2). Eccentric action of net soil pressure under excavation.

At the same time, as shown in Fig. (2), the uniform reaction under the basement becomes uneven reaction. The point of the resultant force of the basement migrates to the excavation point $\mathrm{A}$ and produces eccentricity

$e_{2}=\frac{M_{2}}{G}=\frac{F_{2} H_{2}}{G}$

The overall safety factor can be expressed as follows:

$K=\frac{M}{M_{2}}=\frac{\frac{b}{2} G}{e_{2} G}=\frac{\frac{b}{2}}{e_{2}}$

In general, if $e_{2}$ calculated by equation (1) is less than or equal to $b / 2$, the $K$ is greater than or equal to 1 and the main body's safety is judged by the overturning resistance theory. While, the analysis is only based on the view of the static, and no change of additional stress and additional deformation were considered due to the stress change. Obviously, the coordination of stress and deformation was not considered.

\section{STABILITY EVALUATION CONSIDERING DE- FORMATION}

After the excavation of one side podium foundation pit, the uniform pressure of foundation as shown in Fig. (1), changed to non-uniform eccentric pressure as shown in Fig. (2), due to the difference of soil pressure. The distribution we assumed as uniform would become trapezoidal or triangular. According to the principle of soil mechanics, the additional stress increased accordingly at the side with larger foundation pressure (i.e. the side of excavation) and the settlement has a tendency to increase. While the additional stress decreased at the side with smaller foundation pressure, the settlement has a tendency to decrease and even rebound. That is to say, the uniform deformation caused by original uniform stress has a tendency to change. The settlement of foundation will change with the change of the stress of the basement. Foundation no longer remains horizontal. In this case: (1) A rotation of high buildings along with the foundation may appear with a direction tilt to one side of the foundation pit of garage; (2) At the moment of the foundation rotation, a potential slip line with a certain angle to the hori- 
zontal line along the foundation surface will appear (as shown in Fig. (4)).

Firstly, the rotational trend of foundation is inevitable and the extent of the rotation obviously associates with characters of foundation. In general, the pile foundation can better resist the non-uniform pressure under foundation using the capacity of compression and pullout. The capacity of composite foundation takes second, and the capacity of natural foundation may be the worst. Especially, lateral restraint of the ground soil under the main foundation will be decreased after the excavation of foundation pit. The modulus of foundation soil may be damaged. All of these changes will reduce the resistance ability of rotational deformation of foundation.

Secondly, main body also has a tendency of slipping to the direction of foundation pit excavation along with the potential sliding line under the component force $F_{31}$ of horizontal soil force and component force $G_{1}$ of force $G$. All these component forces had an effect on the ability of the slip resistance. If the foundation is pile foundation, a shear force will exist. The condition of pile will be either a state of pull-shear or compression-shear stress.

Due to the complexity of geotechnical engineering, even if pile foundation is used, an obvious rotation of foundation and sliding may occur. If the bearing capacity of pile (especially the pipe pile) exceeds, the tensile shear failure of foundation piles may occur first. Larger rotation and sliding of the body structure will be produced. An extreme case such as floor collapsing may occur.

Based on the above analysis, after the soil pressure difference and overturning moment is occurred, the stress of main body foundation is eccentric. In this case, the additional effects of overturning moment and the rotation tendency caused by the eccentric force on the stability of main body foundation will be ignored if the traditional static loading analysis was used. In fact, the stability evaluation of a high building and the foundation should be a process in which the stress and deformation are combined for interplay of harmonization between each other. But because of the complexity of geotechnical engineering, the overall stability of stress and deformation of the foundation could not get better unification consideration. At this stage, the more effective way was simulation such as the finite element methods [6]. However, the reliability excessively depends on the constitutive model and the initial data. So, the simulation method has great limitations and is not easy to be mastered by engineers. In practical engineering, the analysis method of overall stability considering deformation was needed based on classical mechanics. This new method with the clear concept in stress and coordination and control in deformation, was easy to be understood and applied for engineers in the engineering application.

\section{EXAMPLE ANALYSIS}

In order to simplify the analysis, no further analysis of the foundation was presented. Only the changes of stability coefficient of main structure after the foundation rotation occurred were considered. As shown in Fig. (3), assumes that the eccentricity $e_{3}=b / 6$ be produced, because of net earth pressure increased from zero to the $\mathrm{F}_{3}$ after excavation.
According to the principles of soil mechanics, the uniform rectangular stress distribution of basement with stress $=\mathrm{G} / \mathrm{b}$ becomes a triangular distribution with $\mathrm{fmax}=2 \mathrm{G} / \mathrm{b}$ and fmin $=0$.

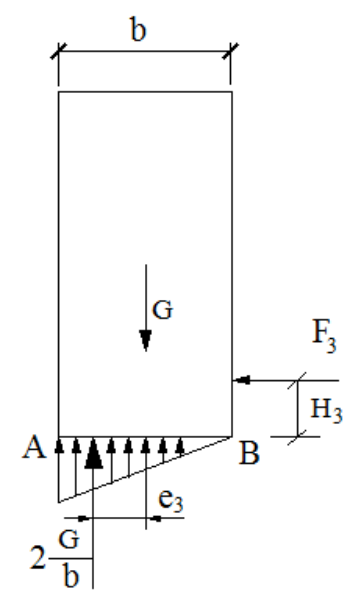

Fig. (3). Counterforce of basement about triangular distribution.

Assuming that no rotation of the main structure occurred and foundation was keep horizontally, the generated eccentric moment can be expressed as follows:

$$
M_{3}=F_{3} \cdot H_{3}=e_{3} \cdot G=\frac{b}{6} \cdot G
$$

Therefore, the overturning moment produced by net soil pressure $\mathrm{F}_{3}$ is $\frac{b}{6} G$. And the overturning resistance moment of the main structure is $\frac{b}{2} G$.

At this moment, the overall stability safety factor is:

$$
K_{3}=\frac{\frac{b}{2} G}{\frac{b}{6} G}=3
$$

This above numerical example was known by many geotechnical engineers.

As mentioned above, traditional methods focus on the force analysis, the calculation and balance of force, and moment, while the deformation due to the change of the force was ignored. No attention was paid to the effect of the nonuniform deformation on the overall stability of the main structure. In fact, in this case, the weaker the foundation was, the greater the settlement difference of foundation under the same overturning moment was produced and the larger the angle to the horizontal plane was. The overall stability safety factor of the structure was no longer 3 and will vary with the tilt angle.

In this example, the regional pressure of point $\mathrm{A}$ increased two times of the original. The additional stress of foundation was increased accordingly. Thus, the additional settlement will be generated downward. The regional pressure of point $B$ was decreased to zero and the additional stress of the foundation was also reduced. An upward rebound will appear. The foundation represented by $\mathrm{AB}$ will 
rotate around a point between the two points. The rotation angle or amplitude was not only related to the additional stress of the foundation, but also related to the compression modulus of foundation soil. But the final result was that a rotation in the direction of foundation pit excavation occurred.

The existing research and practice shows that the settlement calculation of high building relies on the compression modulus (or deformation) of the foundation soil. For the rebound deformation, the rebound deformation modulus will be involved. The rotation analysis of foundation would be complex if analyzed based on this aspect. By changing the way of thinking, the differential settlement between A and B can be calculated referring to the triangle load on rectangular area listed on standard [1]. The method calculated not only the resilience but also the settlement directly, and was more reasonable and well operational at the stage of the main structure capping and the settlement not finished yet. Then, the stability safety factor calculated based on loading was changed when considering the rotation angle of foundation produced by the differential settlement.

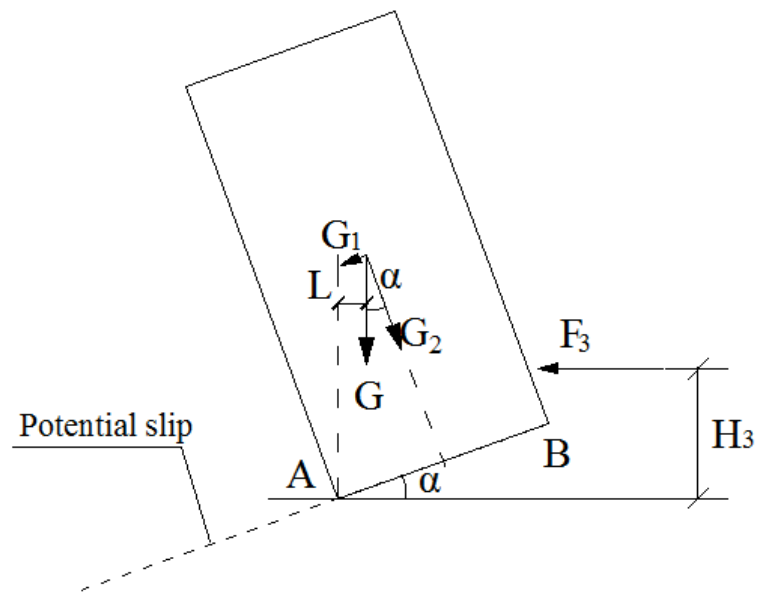

Fig. (4). Inclination of high buildings.

As shown in Fig. (4), assuming that the rotation was around the point $\mathrm{A}, \mathrm{AB}$ has an angle with horizontal direc- tion after tilting. The direction of force $\mathrm{G}$ kept vertically downward but not vertical to foundation side AB. The angle to the original direction was $\alpha$. The actual arm of overturning resistance force could be derived by:

$L=\left(\frac{b}{2}-\operatorname{tg} \alpha \cdot \frac{H}{2}\right) \cos \alpha$

$=\frac{b}{2}\left(1-\operatorname{tg} \alpha \cdot \frac{H}{b}\right) \cos \alpha$

$=\frac{b}{2}(1-\operatorname{tg} \alpha \cdot m) \cos \alpha$

Divided by the width of foundation $b$ at both sides of the above equation, the unit overturning resistance force arm $n$ could be obtained:

$n=\frac{L}{b}=\frac{1}{2}(1-\operatorname{tg} \alpha \cdot m) \cos \alpha$

where $0 \leq \alpha \leq \operatorname{arctg}\left(\frac{1}{m}\right), m$ is the height to width ratio of the building.

The values of $n$ varied with the inclination angle $\alpha$ and the values of $m$ could be calculated using Equation (4). The results were listed in Table $\mathbf{1 .}$

Here, the height to width ratio $m$ equals to $1,2,3,4,5,6$ was considered respectively to investigate the change of unit overturning resistance force arm $n$ with the increase of the inclination angle $\alpha$. At the $\alpha$ ranged from $0^{\circ}$ to $45^{\circ}$, as shown in Table 1, $n$ decreases monotonously with the increase of $\alpha$. And the bigger the height to width ratios $m$ are, the faster the decrease in $n$, and the smaller the inclination angle allowed. Obviously, overturning resistance arm L has physical meaning within $0 \sim 0.5 \mathrm{~b}$. The overturning resistance moment of $\mathrm{G}$ related to point $\mathrm{A}$ also changes with a trend of decrease.

$M=\frac{b}{2}(1-\operatorname{tg} \alpha \cdot m) \cos \alpha \cdot G$

Table 1. Values of $\mathbf{n}$ and $\mathbf{m}$ with different Angles of $\alpha$.

\begin{tabular}{|c|c|c|c|c|c|c|}
\hline $\mathbf{m}$ & $\mathbf{1}$ & $\mathbf{2}$ & $\mathbf{3}$ & $\mathbf{4}$ & $\mathbf{5}$ \\
\hline \hline $5^{\circ}$ & 0.45 & 0.41 & 0.37 & 0.32 & 0.28 & 0.24 \\
\hline $10^{\circ}$ & 0.41 & 0.32 & 0.23 & 0.15 & -0.03 \\
\hline $15^{\circ}$ & 0.35 & 0.22 & 0.09 & -0.03 & -0.16 & -0.38 \\
\hline $20^{\circ}$ & 0.30 & 0.13 & -0.04 & -0.21 & -0.60 & -0.29 \\
\hline $25^{\circ}$ & 0.24 & 0.03 & -0.18 & -0.39 & -0.82 & -1.07 \\
\hline $30^{\circ}$ & 0.18 & -0.07 & -0.32 & -0.57 & -1.02 & -1.31 \\
\hline $35^{\circ}$ & 0.12 & -0.16 & -0.45 & -0.74 & -1.22 & -1.54 \\
\hline $40^{\circ}$ & 0.06 & -0.26 & -0.58 & -0.90 & -1.41 \\
\hline $45^{\circ}$ & 0.00 & -0.35 & -0.71 & -1.06 & \\
\hline
\end{tabular}


The overturning moment was the same as above:

$M_{3}=\mathrm{e}_{3} \cdot G=\frac{\mathrm{b}}{6} \cdot G$

The overturning resistance stability safety factor could be expressed as follows:

$$
K_{4}=\frac{\frac{\mathrm{b}}{2}(1-\operatorname{tg} \alpha \cdot \mathrm{m}) \cos \alpha \cdot \mathrm{G}}{\frac{\mathrm{b}}{6} \mathrm{G}}=3(1-\operatorname{tg} \alpha \cdot \mathrm{m}) \cos \alpha
$$

Assuming that the tilt value of main structure of the high building with weight to width ratio $m$ equals to $1,2,3,4,5,6$ reached allowable value of $0.0025\left(60<\mathrm{H}_{\mathrm{g}} \leq 100=\right.$ of standard [1] respectively (i.e. $\operatorname{tg} \alpha=0.0025, \cos \alpha \approx 1$ ), substitute to Equation (5), we could get $\mathrm{K}_{4}=2.9925(\mathrm{~m}=1), 2.985(\mathrm{~m}=2)$, $2.9775(\mathrm{~m}=3), 2.97(\mathrm{~m}=4), 2.9625(\mathrm{~m}=5), 2.955(\mathrm{~m}=6)$ separately. All the results demonstrated that the overall stability safety coefficients considered that the deformations were less than safety factor $(\mathrm{K} 3=3)$ which were calculated using the traditional method which only considered the stress.

The results of calculated safe factors when the angle $\alpha$ ranged from $0^{\circ}$ to $10^{\circ}$, are shown in Fig. (5). Fig. (5) presents that once the rotation was produced by the non-uniform deformation, the overturning resistance moments of main structure will decrease with the increase of the inclination angle. Meanwhile, the larger the height to width ratios was, the more the reduction of overturning resistance moment was. Finally, the overall overturning resistance stability safety factor with a non-fixed value was changed with the generation of the foundation tilting and is related to the height to width ratios (as shown in Fig. (6)).

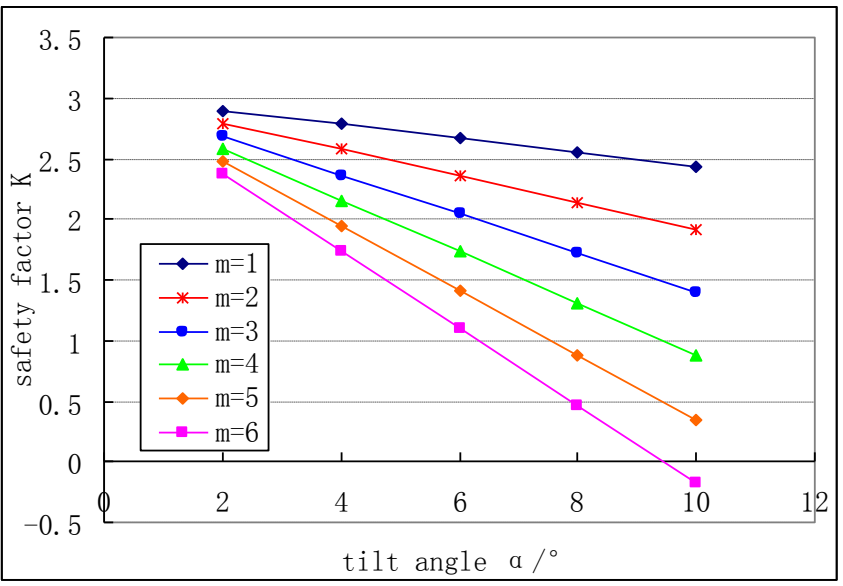

Fig. (5). Variation of Safety Factor with Inclination Angles.

In a word, the values of tilting produced by the main structure under certain overturning resistance moment and the variation of safe factors had relativity with compression properties of foundation. Therefore, the requirement of ground treatment was not only the requirements of strength, but also the ones of deformation by increasing the compression modulus of foundation.

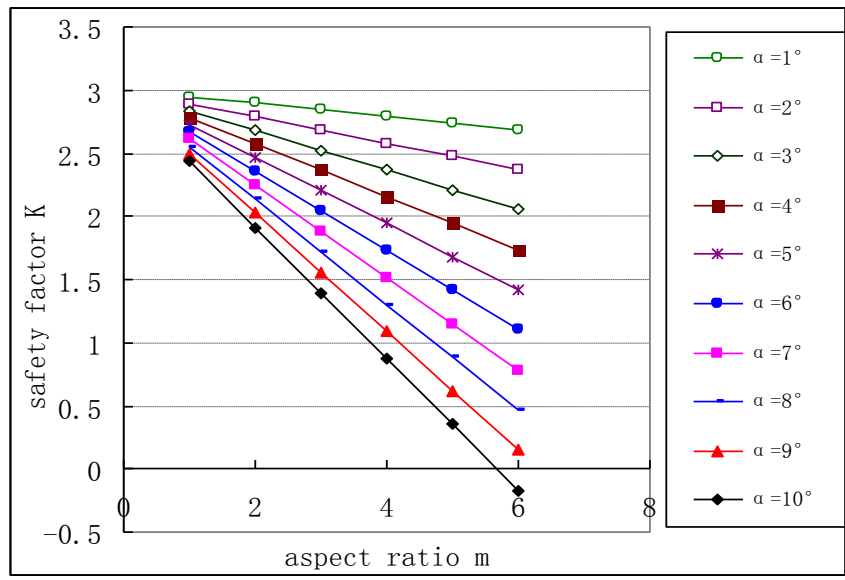

Fig. (6). Variation of Safety Factor with Depth-to-Width Ratios

\section{CONCLUSION}

As stated above, the soil pressure difference was produced due to excavation of foundation pit of podium and garage at the side of high buildings. And the non-uniform pressure and additional stress of foundation appeared. The foundation of main structure had a trend to rotate. The value of inclination angle $\alpha$ of high building was not only had the relationship with the value of net lateral earth pressure, but also related to the compression modulus of foundation soil ranged of the foundation pressure. The compression modulus of foundation soil in different categories is also affected by the damage of compression modulus caused by the change of lateral resistance after excavation. And because of the potential slip line with a certain angle to the horizontal line caused by the foundation rotation, a sliding force of the main structure along the line was produced under the downward action of the earth pressure and the downward component of sliding force. In a word, the effect on high buildings caused by excavation of the garage foundation pit on one side could not be ignored. The change of safety stability factor of overturning resistance was a complex and dynamic process controlled by many factors. This change was the coordinated development process of stress and deformation conditions. Further researches are needed to be done in the future. The analysis in our research was focused on from the structure stress to the deformation of foundation. The new thought with clear mechanism has stronger operational application for the project. Based on these analyses, a new idea about the evaluation of overall overturning resistance stability of high building after the excavation of foundation was proposed in this paper.

\section{CONFLICT OF INTEREST}

The authors confirm that this article content has no conflict of interest.

\section{ACKNOWLEDGEMENTS}

This work is supported by the project of National Natural Science Fund for the Youth, China (No.51208473), the Key project for Science and Technology of Shanxi, China (No.20130313010-3), and the project of Natural Science Fund of Shanxi for the Youth, China (No.2012021019-1). 


\section{REFERENCES}

[1] GB 50007-2011 Code for Design of Building Foundation. The People's Republic of China Ministry of Construction. China Building Industry Press, Beijing: 2011.

[2] H. Y. Wang, and M. Yang, "An estimate for the loss of bearing capacity of the footing near excavations," China Civil Engineering Journal, vol. 38, no. 8, pp. 95-101, 2005.

[3] K. Wang, L. M. Qiu, and D. H. Wu, "Analysis of the influence law brought by deep excavation to the surrounding architecture," Engineering Reconnaissance, no. 6, pp. 30-31, 2004.

[4] J. Shen, Y.L. Li, and J. H. Wang, "Three-dimension numerical analysis brought by deep excavation to the surrounding foundation of the elevated road," Chinese Journal of Underground Space and Engineering, vol. 1, no. 6, pp. 518-521, 2005.

[5] G. Zheng, Z. X. Yan, H.Y. Lei, and Y. Lei, "Field observation and finite element numerical simulation analysis of effect on adjacent piles due to excavation," Chinese Journal of Geotechnical Engineering, vol. 29, no. 5, pp. 638-643, 2007.

[6] E. X. Song, L. Q. Wang, and Y. J. Chi, "Analysis and policy decision for the influence of foundation excavation on adjoining highrise building," Geotechnical Investigation and Surveying, no. 4, pp. 28-31,2001.

[7] M. Bodaqhi, and A. R. Saidi, "Stability analysis of functionally graded rectangular plates under nonlinearly varying in-plane loading resting on elastic foundation," Archive of Applied Mechanics, vol. 81 , no. 6 , pp. $765-780,2011$.

[8] X. J. Chu, "Study on the stability and structural optimization of self-elevating platform pile foundation," Applied Mechanics and Materials, vol. 65, pp. 613-616, 2011.
[9] X. F. Ma, H.H. Zhang, W. J. Zhu, and Y.F. Zheng, and Q.W. Xu, "Centrifugal model tests on effect of excavation super-deep foundation pits on adjacent high-rise buildings," Chinese Journal of Geotechnical Engineering, no. 30, pp. 499-504, 2008.

[10] S. L. Feng, Y. H. Wu, J. Li, P. Lib, Z. Zhangc, and D. Wang, "The analysis of spatial effect of deep foundation pit in soft soil areas," Procedia Earth and Planetary Science, vol. 5, pp. 309-313, 2012.

[11] H. Devolder, O. Pirson, J. Nomerange, A. Monjoie, C. PoloChiapolini, M. Provost, and J.J.Sevillers, "Stability of a large excavation with vertical sides filled with thixotropic clay (In French)," International Journal of Rock Mechanics and Mining Sciences \& Geomechanics, vol. 25, no. 5, pp. 248-258, 1998.

[12] S. Chern, J. H. Tsai, L. K. Chien, and C. Y. Huang, "Predicting ateral wall deflection in top-down excavation by neural network," International Journal of Offshore and Polar Engineering, vol. 19, no. 2, pp. 151-157, 2009.

[13] L. P. Shi, K. T. Chang, and H. Y. Yeh, "Performance evaluation of foundation excavation in Rong Guang building," International Journal of Rock Mechanics and Mining Sciences \& Geomechanics, vol. 26, no. 3-4, pp. 3-4, 1989.

[14] F. Nateghi, and A. Rezaeitabrizi,“ Nonlinear dynamic response of tall buildings considering structure-soil-structure effect,"Structural Design of Tall and Special Buildings, vol. 22, no, 14, pp. 10751082, 2013.

[15] H. G. Poulos, Foundation Design for Tall Buildings, Geotechnical Engineering State of the Art and Practice:Keynote Lectures from GeoCongress, 2012, pp. 786-809.

[16] A. Sinopoli, and A. Ageno, "Stability analysis of a free-standing block with friction on a moving foundation," In: Proceedings of DETC, 2001, p. 1.

(C) Yunshan et al.; Licensee Bentham Open.

This is an open access article licensed under the terms of the Creative Commons Attribution Non-Commercial License (http://creativecommons.org/licenses/ by-nc/4.0/) which permits unrestricted, non-commercial use, distribution and reproduction in any medium, provided the work is properly cited. 